\title{
AS MULHERES E O NOVO CONSTITUCIONALISMO: UMA NARRATIVA FEMINISTA SOBRE A EXPERIÊNCIA BRASILEIRA
}

\section{WOMEN AND THE NEW CONSTITUTIONALISM: A FEMINIST NARRATIVE ABOUT THE BRAZILIAN EXPERIENCE}

\author{
${ }^{1}$ Salete Maria Da Silva \\ ${ }^{2}$ Sonia Jay Wright
}

\section{RESUMO}

O novo constitucionalismo que vem se construindo, paulatinamente, na América Latina tem por base e característica principal a crescente participação popular nos processos políticos que culminaram com a redemocratização dos Estados desta região. Dentre os diversos grupos e movimentos sociais que contribuíram para a inserção de novos direitos nos textos constitucionais latino-americanos, destacam-se os movimentos feministas e de mulheres que, ao longo da década de 1980, passaram a pugnar pela constitucionalização de suas demandas históricas. No Brasil, a exemplo de alguns países vizinhos, as mulheres atuaram decisivamente na Assembleia Nacional Constituinte de 1987/88, articulando democracia participativa e representativa e ampliando, de maneira extraordinária, os direitos de cidadania feminina. Não obstante isto, a historiografia constitucional brasileira tem desconhecido, silenciado e/ou omitido tal fato, contribuindo, ainda mais, para análises e interpretações jurídicas e políticas unidimensionais, androcêntricas e desconectadas da realidade social. Visando preencher esta lacuna, este texto, traz uma narrativa feminista do processo constituinte, baseando-se em análise documental e em entrevistas realizadas com algumas das mais destacadas protagonistas deste momento histórico.

Palavras-chave: Constitucionalismo, Feminismo, Participação, Direitos, Cidadania

\footnotetext{
${ }^{1}$ Doutora em Estudos Interdisciplinares Sobre Mulheres, Gênero e Feminismo pela Universidade Federal da Bahia, UFBA. Professora da Universidade Federal da Bahia, UFBA.

E-mail: saletemaria@oi.com.br

${ }^{2}$ Doutora em Ciências Sociais pela Universidade Estadual do Rio de Janeiro, UERJ. Professora da Universidade Federal da Bahia, UFBA.

E-mail: wri2sonia@hotmail.com
} 


\begin{abstract}
The new constitutionalism that has been being built, little by little, in Latin America, has had its base and main characteristic in an increasing popular participation in the political processes that culminated with the redemocratization of the regions States. Among the several groups and social movements that contributed to the insertion of new rights into the Latin American Constitutional texts, feminist and women movements distinguished themselves along the 1980s for their struggle for the constitutionalization of their historical demands. In Brazil, as in some neighboring countries, women acted decisively in the Constituent National Assembly of 1987/1988, articulating participative and representative democracy, and amplifying, extraordinarily, womens rights as citizens. Nevertheless, Brazilian Constitutional historiography has ignored, silenced and/or omitted this fact, contributing, even more, to one-dimensional, androcentric and disconnected from social reality analysis and juridical/political interpretations. Aiming to fulfill this gap, this text, brings a feminist narrative of the Constituent process, based on documental analysis and on interviews with some of the most distinguished participants of this historical moment.
\end{abstract}

Keywords: Constitutionalism, Feminism, Participation, Rights, Citizenship 


\section{INTRODUÇÃO}

Diversos estudiosos dos campos jurídico e político tem voltado seu olhar para o que se convencionou chamar de novo constitucionalismo latino-americano, pondo ênfase, sobretudo, nos processos de elaboração dos textos constitucionais e nos novos conteúdos resultantes das mudanças verificadas nas últimas três décadas neste espaço geopolítico (DALMAU, 2003, 2008; SANTOS, 2007; FAJARDO, 2011).

Sobre este último aspecto, os autores mencionados chamam atenção para o fato de que as atuais Constituições de países como Brasil 1988, Colômbia 1991, Argentina 1994 e Venezuela 1999, foram elaboradas ou reformadas após a vigência de ditaduras militares e da aplicação de políticas neoliberais em seus territórios, o que torna possível a afirmação de uma nova fase do constitucionalismo na região. Além disto, há quem destaque que as Constituições da Bolívia e do Equador trazem em seus conteúdos um "projeto de implementação de um Estado plurinacional", assim como a "criação de mecanismos de democracia participativa e a possibilidade de intervenção estatal na economia.” (LEAL e VIEIRA, 2013, p. 1)

Com relação ao processo de elaboração dos textos constitucionais mencionados, podese dizer que este novo constitucionalismo, paulatinamente construído na América Latina, tem por base e característica principal a crescente participação popular, forjada nas lutas em prol da redemocratização dos Estados desta região. Para autores como Cadermartori e Costa (2013, p. 223) esse novo paradigma exige que

\footnotetext{
O conteúdo da Constituição deve ser coerente com a sua fundamentação democrática, isto é, deve gerar mecanismos para a direta participação política da cidadania, gerando regras que limitem os poderes políticos, sociais, econômicos e culturais, de modo a enfatizar o fundamento democrático da vida social e os direitos e liberdades da cidadania. Este novo constitucionalismo além de pretender garantir um real controle sobre o poder por parte dos cidadãos busca solucionar o problema da desigualdade social. (grifo nosso)
}

Pelo exposto, percebe-se que o novo movimento constitucional latino-americano valoriza a participação cidadã e a inclusão social por meio dos direitos fundamentais, pois, conforme Morais e Barros (2013, p. 1), é “com um olhar democrático para sociedades e grupos oprimidos e colonizados, [que estes Estados vem] promovendo o reconhecimento de novos direitos fundamentais, em consonância com o direito da diversidade, da mãe terra e do meio ambiente." Corroborando esta perspectiva, dentre os diversos grupos e movimentos sociais que contribuíram para a inserção de novos direitos nos textos constitucionais latino-americanos, 
destacam-se os movimentos feministas e de mulheres que, ao longo das décadas de 1970 e 1980, passaram a pugnar pela constitucionalização de suas demandas históricas (SILVA, 2012).

No Brasil, a exemplo de alguns países vizinhos ${ }^{1}$, as mulheres atuaram decisivamente na Assembleia Nacional Constituinte de 1987/88, obtendo inúmeras conquistas voltadas para a ampliação da cidadania feminina. Apesar disto, a historiografia constitucional brasileira tem desconhecido, silenciado e/ou omitido tal fato, contribuindo, ainda mais, para análises e interpretações jurídicas e políticas unidimensionais, androcêntricas ${ }^{2}$ e desconectadas da realidade social.

Visando preencher esta lacuna, este texto, que é fruto de um aprofundado estudo sobre o famigerado lobby do batom $^{3}$, traz uma narrativa não androcêntrica do processo constituinte, visibilizando a participação das mulheres e o legado jurídico-político desta decorrente, baseando-se em análise documental ${ }^{4}$ e em entrevistas semiestruturada ${ }^{5}$ realizadas com onze das mais destacadas militantes feministas que protagonizaram este momento histórico. Este artigo, portanto, apresenta e discute alguns dados desta pesquisa, pondo em relevo um aspecto pouco explorado pelos demais estudiosos do tema, qual seja, a contribuição das mulheres para a

\footnotetext{
${ }^{1}$ Paralelamente à experiência brasileira, entre junho e julho de 1987 realizou-se em Buenos Aires um Seminário intitulado "Las mujeres y la reforma constitucional" que deu origem a um livro homônimo publicado, no mesmo ano, pela Fundación Arturo Illia para la democracia y la paz. Foi convidada para tomar parte neste evento a jurista brasileira Silvia Pimentel, a quem coube falar sobre as estratégias das mulheres brasileiras para fazer inserir no seio da Constituição suas demandas históricas. Este evento

2 O termo decorre do conceito de androcentrismo, ou seja, uma visão de mundo que toma o masculino como referente, parâmetro e modelo do humano. Trata-se de uma das formas de manifestação do sexismo que, por sua vez, consiste na crença, fundamenta em mitos, na superioridade de um sexo sobre o outro, o qual, em sociedades patriarcais, corresponde ao sexo masculino.

3 Grupo de pressão que atuou na Assembleia Constituinte de 1987/88, composto por mulheres parlamentares e lideranças sociais.

4 A análise foi feita a partir de documentos localizados no Arquivo Nacional (sediado em Brasília-DF) tais como: arquivos do Conselho Nacional dos Direitos da Mulher-CNDM (Projeto e programação da Campanha Mulher e Constituinte, relatórios das atividades realizadas, atas de reuniões relativas à ação das conselheiras e técnicas do CNDM, correspondências com entidades de mulheres de todo o país, a Carta das Mulheres aos Constituintes, folderes e cartazes de eventos sobre Mulher e Constituinte, matérias jornalísticas sobre o lobby do batom, solicitações do Conselho a órgãos governamentais, cópias dos conteúdos das emendas populares sobre os direitos das mulheres, registros de acompanhamento das votações no Plenário da Assembleia, dentre outros. Anais da Constituinte, agenda das atividades, álbum de fotos, memórias da Constituinte e diversas edições de jornais da época, inclusive com notícias sobre a participação das mulheres, tais como: Jornal da Constituinte, Correio Braziliense, Folha de São Paulo, O Globo, Jornal do Brasil, Jornal de Brasília, Jornal da Tarde, O Estado de São Paulo e Gazeta Mercantil, etc. Além do acervo particular de algumas entrevistadas, contendo fotos, recortes de jornal, correspondências, cartazes e panfletos, etc.

5 As entrevistas foram realizadas entre os anos de 2008 e 2010, em cinco estados da federação, e mais o distrito federal, com feministas que participaram ativamente do lobby do batom. São elas: Jacqueline Pitanguy (RJ):

presidente do Conselho Nacional dos Direitos da Mulher-CNDM entre 1986 e 1989; Maria Amélia de Almeida Teles (SP): fundadora e militante da União de Mulheres de São Paulo; Schuma Shummaer (RJ): secretária executiva do CNDM e diretora de articulação política do mencionado Conselho à época da Constituinte; Ana Maria Rattes (RJ): deputada constituinte pelo PMDB (1987/88) e segunda vicepresidente da Comissão de Soberania e dos Direitos e Garantias do Homem e da Mulher na Constituinte; Hildete Mello (RJ): conselheira do CNDM entre 1985 a 1989; Comba Marques Porto (RJ): advogada responsável por palestras e seminários sobre Constituição e direitos das mulheres em diversos estados do país; Marlene Libardone (DF): membro do CNDM e coordenadora da Comissão de estudos e propostas sobre Mulher e Trabalho; Gilda Cabral (DF): membro do CNDM e coordenadora da Campanha Mulher e Constituinte; Lúcia Porfírio Homem (MG): dona de casa e presidente do Movimento das Donas de Casa e Consumidores de Minas Gerais; Moema Viezzer (PR): coordenadora da Rede Mulher de Educação, defensora, na tribuna da Constituinte, da emenda popular denominada Direitos da Mulher; Antônia Garcia (BA): líder comunitária e membro da Federação das Associações de Bairro de Salvador- FABS, atuou na coleta de assinaturas em prol da aposentadoria das donas de casa e nas discussões sobre a importância da participação popular na Constituinte.
} 
construção dos seus direitos constitucionais. Trata-se, portanto, de um aporte aos estudos da história do direito, mais particularmente da constitucionalização dos direitos das mulheres no Brasil.

A análise teórica é feita à luz das teorias feministas, inspirando-se especialmente nas contribuições de pesquisadoras que se debruçam sobre as temáticas de gênero e direito, gênero e história e gênero e poder (FACIO, 1999; COSTA; PHILLIPS, 2001; PINTO, 1994) dentre outras para quem as experiências de participação das mulheres no espaço público, mais especificamente no Parlamento, foram fundamentais para a constitucionalização de seus direitos. O presente texto destaca que, em face da posição desigual das mulheres nos espaços de poder, foi necessária a articulação de democracia representativa e democracia participativa, materializada tanto na presença de mulheres enquanto deputadas e senadoras, como na incorporação das vozes, ideias e demandas femininas apresentadas pelas próprias feministas, através de grupos de pressão atuantes no âmbito dos poderes constituídos.

Visando evidenciar e discutir a experiência mencionada, o presente texto se desdobra em três tópicos específicos: o primeiro traz a ideia de constitucionalismo e de Constituição enquanto constructos históricos e culturais marcadamente androcêntricos; o segundo, destaca a participação das mulheres na construção de seus direitos constitucionais, com vistas a mudar o velho paradigma; e o terceiro apresenta e discute a presença, as demandas e as conquistas femininas no âmbito da Assembleia Nacional Constituinte de 1987/88.

\section{CONSTITUCIONALISMO E CONSTITUIÇÃO: CONSTRUCTOS HISTÓRICOS, CULTURAIS E ANDROCÊNTRICOS}

A experiência constitucionalista mundial, assim como a latino-americana e brasileira, não constitui um movimento linear e harmônico, pois faz parte de um longo processo histórico, marcado por avanços e, sobretudo, por incongruências e exclusões, notadamente de mulheres e de outros grupos historicamente discriminados. O nascimento do constitucionalismo moderno ${ }^{6}$

\footnotetext{
6 Não é objeto deste artigo elucubrar sobre a origem do constitucionalismo moderno, mas vale registrar que, segundo diversos autores, sua gênese está associada à emergência das revoluções burguesas na Inglaterra 1688, Estados Unidos 1776 e França 1789, com suas respectivas Constituições voltadas à limitação do poder do Estado e a declaração dos Direitos fundamentais da pessoa humana.
} 
marca o início do Estado Liberal e a adoção do modelo econômico e político homônimo que, durante anos, foi expressamente garantido pelas normas constitucionais. Vale destacar que a essência deste constitucionalismo, que é marcadamente androcêntrico, está na construção do individualismo e da proclamada liberdade individual, construída sobre os fundamentos da omissão estatal e da proteção da propriedade privada. Neste período, a cidadania é conferida exclusiva e naturalmente ao homem, enquanto macho da espécie humana, que, pelas leis da época, já nasce livre e igual. ${ }^{7}$

No período acima mencionado, em todos os Estados constitucionais, as mulheres não eram consideradas sujeitos políticos e, portanto, não participavam dos processos de tomada de decisão $^{8}$ e elaboração das normas estatais, não obtendo, portanto, sua proteção e seu reconhecimento enquanto sujeitos de direitos e seres autônomos e capazes. Porém, esta não é uma característica exclusiva desta primeira fase de constitucionalismo e de suas respectivas Constituições; trata-se de uma realidade que também vai estar presente na segunda geração constitucional que emergirá no final da década de 1940.

A partir do pós segunda guerra mundial, em razão dos incalculáveis prejuízos econômicos e sociais decorrentes das intervenções bélicas, surge um novo constitucionalismo no mundo, já com novas feições, mas mantendo o viés androcêntrico. Este novo constitucionalismo é caracterizado pela imposição de certa preocupação ética e humanística com relação à elaboração e ao conteúdo das normas que regem a atuação do Estado. Neste momento surge o chamado neoconstitucionalismo de base europeia, segundo o qual

Um Estado só será um Estado constitucional se contar com uma Constituição em sentido substancial/material, fruto da legitimidade democrática, bem como, com instrumentos que garantam a limitação do poder e a efetividade dos direitos fundamentais. (CADERMARTORI; COSTA, 2013, P. 221)

O chamado neoconstitucionalismo e sua ideia de Estado Constitucional passa pela verificação da efetivação de dois elementos fundamentais: a legitimidade democrática e a normatividade. No entanto, em termos de América Latina, dada suas características muito particulares, e levando-se em conta o contexto em que as novas Constituições foram elaboradas, a nomenclatura atribuída oscila entre

\footnotetext{
7 Vale destacar que esta igualdade não é conferida a todos os homens e nem em todos os lugares, dada as inúmeras restrições impostas em razão da classe social e da raça/etnia, sobre o que, infelizmente, não há como discutir no presente texto.

8 Não estou afirmando que as mulheres não participavam das lutas sociais ou mesmo da construção das ideias que culminaram com as primeiras declarações de direitos instituídas pelos Estados nacionais, haja vista que durante a Revolução Francesa mulheres como Olympe de Gouges participaram ativa e tenazmente em prol da ideia de igualdade, liberdade e fraternidade. Estou me referindo ao fato de não terem assentos nas assembleias e, por isto, não poderem tomar parte na votação das normas que estabeleciam o chamado pacto social.
} 
termos como "novo constitucionalismo, constitucionalismo andino, ou constitucionalismo de terceira geração" (DALMAU, 2008, p. 6), visando se diferenciar da experiência europeia, cujo pano de fundo, em termos de realidade política, econômica e social, é completamente diferente. Vale destacar que, nesta região, é somente a partir do final da década de 1980 e início da década de 1990 é que os Estados passam a adotar Constituições que trazem respostas inovadoras à chamada crise constitucional. E é neste contexto que se propõe a superação do "conceito de Constituição como mero limite ao poder constituído na proporção em que avançam ao apresentar uma fórmula democrática em que o poder constituinte expressa sua vontade também sobre a configuração e limitação da própria sociedade." (CADERMARTORI; COSTA, 2013, P. 221).

No entanto, apesar do avanço em termos históricos, políticos e sociais, nem os Parlamentos e nem a Ciência (Política ou Constitucional) latino americanas se deram conta de que o tecido social também é composto por mulheres e que estas, por sua vez, apresentam necessidades e demandas bastante específicas. Diante disto, o movimento feminista latinoamericano, que na década de 1980 já se encontrava razoavelmente organizado, percebendo a importância de se criar e manter uma boa interlocução com o Estado, passa a interferir na construção de políticas e na elaboração dos textos constitucionais com vistas a pleitear direitos para as mulheres e ampliar a cidadania feminina (COSTA, 2005; SILVA, 2012). Assim, malgrado a cegueira de gênero ${ }^{9}$ presente nas práticas e reflexões políticas desenvolvidas na região, a América Latina, e o Brasil em particular, passa a testemunhar uma experiência jamais vista anteriormente: a presença e a pressão política das mulheres nas Assembleias Constituintes, em defesa de seus direitos.

No caso do Brasil, a situação é bastante singular, pois, além de ser um dos primeiros países da região a experimentar este processo de redemocratização e elaboração constitucional com ampla participação social, após 21 anos de ditadura militar, o fez com a presença não somente de forças políticas de esquerda e de movimentos sociais que representam ideias progressistas, mas com a ampla e organizada participação das mulheres, dentre elas muitas feministas, atuando no âmbito e no entorno da Assembleia Constituinte. Este fenômeno ficou conhecido como lobby do batom, ou seja, como um grupo de pressão que soube articular elementos de democracia participativa e representativa e, juntamente com outros atores políticos, soube se fazer ouvir, a ponto de também influenciar a produção da assim chamada Constituição cidadã (SILVA, 2009).

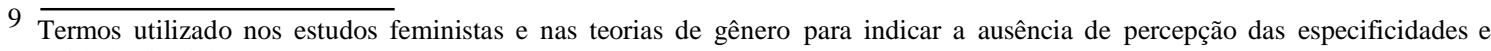
ecessidades femininas.
} 
Essa experiência de participação política das mulheres no seio do Parlamento brasileiro merece destaque porque se deu num contexto em que o lobby do batom atuou como uma espécie de ponte ${ }^{10}$ (AVELAR, 2007) entre os movimentos de mulheres e a política formal, gerando impactos importantes no processo decisório que culminou com a constitucionalização dos direitos das mulheres no Brasil.

Para uma melhor percepção da importância da ação deste grupo de pressão dentro do Parlamento, vale destacar que, ao longo de seus 192 anos de independência, o Brasil já elaborou oito Constituições, sendo quatro impostas pelos governantes e quatro votadas por assembleias constituintes; no entanto, até 1986, apenas uma mulher havia sido eleita deputada constituinte: a médica paulista Carlota Pereira de Queiroz que, em 1934, atuou junto ao parlamento nacional na elaboração da Lei Maior. Todavia, pelas próprias condições da época, sua participação foi acanhada, pois, diferentemente da experiência discutida neste artigo, a Assembleia Constituinte de 1933 não contou com a ampla mobilização e participação feminina, uma vez que neste período o feminismo no Brasil não tinha o mesmo acúmulo prático e teórico que ostentou em 1987/88 e ostenta nos dias atuais. Assim, em que pese a conquista do direito ao voto em 1932, recepcionado e ampliado pela Constituição de 1934, não se pode destacar avanços em termos de direitos da mulher nesta norma superior, tampouco nas demais que a sucederam ${ }^{11}$ (SILVA, 2012).

Em face disto, até a promulgação da atual Constituição brasileira, as leis no Brasil (constitucionais ou infraconstitucionais), sempre tiveram um caráter flagrantemente masculino e androcêntrico, reforçando preconceitos e gerando discriminações contra a parcela feminina da sociedade. A Constituição Federal em vigor, portanto, significou, no plano jurídico nacional, um marco legislativo no tocante aos direitos das mulheres e à ampliação de sua cidadania. Esta conquista, todavia, não deve ser creditada, como insistem alguns, aos bons ventos democráticos que pairavam sobre o Parlamento brasileiro e que o levou a outorgar à parcela feminina da população alguns direitos fundamentais; mas, ao contrário, deve ser atribuída, principalmente, à inaudita articulação política das próprias mulheres no seio da Constituinte, que, através das

\footnotetext{
10 A importância de se estabelecer pontes entre a política formal e os movimentos sociais é explorada pela cientista política Lúcia Avelar, em artigo intitulado "Dos movimentos aos partidos: a sociedade organizada e a política formal", onde a mesma faz menção ao "velho e bom debate sobre democracia representativa e participativa" destacando que "é inadiável o debate sobre essa ponte para que se atue no nível das instituições. Trata-se de uma provocação sobre os limites de fazer-se política longe dos corpos representativos e das arenas decisórias, centrando a participação na sociedade organizada" (2007, p. 112),

11 As Constituições de 1937, 1946, 1967 e 1969 em nada inovaram com relação aos direitos das mulheres, pois sequer trataram de temas relativos à igualdade de gênero.
} 
26 deputadas eleitas ${ }^{12}$ e, sobretudo, por meio da pressão exercida pelo movimento feminista e de mulheres, conseguiu, mobilizando o Brasil de norte a sul e de leste a oeste, sensibilizar parlamentares e pressionar outros tantos a fim de que elas mesmas pudessem apresentar emendas populares capazes de eliminar séculos de subordinação legal das mulheres e colocar em discussão sua exclusão das instâncias de poder.

Como se vê, o novo constitucionalismo latino-americano, no qual está inserido a experiência constitucional brasileira, e a Constituição deste decorrente, tem feições femininas que borram um pouco o velho paradigma androcêntrico, demonstrando que também é fruto de um constructo histórico e cultural bastante específico e singular, que vai se desenhando e se consolidando por meio de importantes lutas sociais, dentre as quais se destacam a organização e mobilização das mulheres latino-americanas, particularmente as brasileiras, tão diversas em sua composição étnica, racial, geracional, sexual e cultural, mas unidas em prol da desconstrução da cultural patriarcal.

\section{A PARTICIPAÇÃo das MULhERES NA CONSTRUÇÃo DE DIREITOS CONSTITUCIONAIS}

Segundo Norberto Bobbio (1992, p. 5) os direitos humanos "por mais fundamentais que sejam, são direitos históricos," isto é, são construídos em certas circunstâncias que, não raro, são marcadas por aguerridas e destacadas lutas sociais. Assim, e exatamente por serem históricos, não surgem, como diz o mencionado autor, "de uma única vez e nem de uma vez por todas". Ademais, em se tratando dos direitos das mulheres, a história em prol desta conquista tem sido pontilhada, no mundo e no Brasil, por inúmeras lutas onde se registram avanços e recuos, num longo processo impulsionado pelos movimentos feministas que, consoante destacam algumas pesquisadoras (SARDENBERG; COSTA 2012; PINTO, 2003; ALVAREZ, 1998), não pode ser caracterizado como um movimento retilíneo, uniforme e unívoco, mas recheado de complexas discussões, variadas demandas e dinâmicas difíceis de ser acompanhadas e compreendidas "por quem não vivencia suas entranhas." (COSTA, 2005, p. 9).

A luta das mulheres brasileiras em prol de sua cidadania, a exemplo do que acontece com outras mulheres em outros lugares do globo, é uma batalha bastante antiga, mas ao mesmo

\footnotetext{
12 Eram elas: Sadie Hauache, Sandra Cavalcante, Abigail Feitosa, Anna Maria Rattes, Benedita da Silva, Bete Mendes, Beth Azize, Cristina Tavares, Dirce Tutu Quadros, Eunice Michiles, Lídice da Mata, Lúcia Braga, Lúcia Vânia, Márcia Kubistschek, Maria de Lourdes Abadia, Maria Lúcia, Marluce Pinto, Moema São Tiago , Myrian Portella, Raquel Cândido, Raquel Capiberibe, Rita Camata, Rita Furtado e Rose de Freitas.
} 
tempo muito atual, podendo ser caracteriza, conforme bem disse Juliet Mitchel (1967, p. 1), como a "a mais longa revolução" da história humana.

Vale destacar que esta luta, notadamente a que se dá no âmbito do Parlamento, envolve pressões, articulações, negociações e, às vezes, alguns recuos, além de algumas denúncias contra atores políticos resistentes às mudanças sociais. Trata-se de um grande aprendizado para as mulheres, inclusive as mais experientes militantes políticas pois, historicamente, dada a persistência da velha dicotomia entre os espaços público e privado, aa parcela feminina da população esteve, para usar uma expressão de Costa (1998, p. 19), "do outro lado do poder".

No caso em apreço, a participação das mulheres na construção de seus direitos constitucionais exigiu muita argúcia, muita habilidade política, muita compreensão da conjuntura política e do próprio funcionamento Parlamentar por parte das feministas, notadamente aquelas com participação nas estruturas do Estado, através do Conselho Nacional dos Direitos das Mulher, que, por força da responsabilidade que assumiram, tiveram que conhecer o Poder Legislativo por dentro, em suas entranhas, desvelando o seu funcionamento e o jogo de poder a fim de entender e mobilizar todas as possibilidades de intervenção política. Tudo isto resulto na concretização do que Anne Philips (2001) chama de articulação entre política das ideias e política da presença, ou seja, na potencialização da democracia representativa e na inclusão das pautas feministas no debate político.

Foi neste contexto que o sujeito político mulheres, acostumando com a participação política informal (nos movimentos e grupos de reflexão que se constituíram a partir do longo do período ditatorial), passou a compreender e valorizar a participação política formal (no âmbito dos partidos políticos) e, sobretudo, estatal (como parlamentares), uma vez que ficou patente a importância da norma constitucional para o avanço da cidadania feminina (AVELAR, 2007; COSTA, 2005; PINTO 2003). Para uma melhor compreensão de tais questões, destacase, a seguir, alguns aspectos desta participação feminina.

\subsection{A PRESENÇA, AS DEMANDAS E AS CONQUISTAS FEMININAS NA CONSTITUINTE DE 1987/88}

Os dados coletados na pesquisa demonstraram que, com o amplo apoio do Conselho Nacional dos Direitos da Mulher-CNDM, foi lançada, em 1985, a campanha Mulher e Constituinte, cujo lema era: "Constituinte prá valer tem que ter palavra de mulher". 
Esta campanha permitiu que discussões e debates acontecessem, durante meses, por todo o país, resultando na elaboração da "Carta da Mulher Brasileira aos Constituintes", que foi entregue ao

Congresso Nacional no dia 26 de agosto de 1986, pelas mãos de mais de mil mulheres, numa atuação que, no processo constituinte, ficou publicamente caracterizada como o lobby do batom.

Esta carta, sistematizadora de reivindicações que foram transformadas em direitos constitucionais, foi o símbolo de todo esse processo, talvez um dos maiores na história do movimento de mulheres brasileiro. No entanto, tudo isto somente foi possível porque o movimento feminista brasileiro, que participou ativamente das lutas pela redemocratização do país, estava significativamente maduro em termos de interlocução dos grupos entre si, destes com os partidos políticos, notadamente os de esquerda, e também com o próprio Estado, de quem já vinha se aproximando em face da criação dos conselhos de direitos da mulher, institucionalizados desde 1982 em alguns estados e capitais (COSTA, 2005, p 17). Portanto, conforme destaca Pinto (1994, p. 263), “o movimento [feminista] via CNDM teve decisiva atuação no processo constituinte de 1987-88, conseguindo ganhos de alto significado.”

Juridicamente falando, as mulheres obtiveram diversas conquistas, pois a Constituição Federal acolheu diversas demandas do movimento de mulheres, a começar pela garantia do princípio da igualdade jurídica, que trouxe importantes desdobramentos e influenciou a interpretação de leis e outras normas infraconstitucionais. Em termos quantitativos, cerca de $80 \%$ das reivindicações foram incorporadas ao texto constitucional e convertidas em direitos fundamentais. Em face da pressão exercida pela organização e mobilização das mulheres, a Constituição estabeleceu, expressamente, em seu artigo $5^{\circ}$, inciso I, que "homens e mulheres são iguais em direitos e obrigações", e no inciso XLI deste mesmo artigo advertiu que "a lei punirá qualquer discriminação atentatória aos direitos e liberdades fundamentais".

Além disto, o princípio constitucional da igualdade foi contemplado também no âmbito das relações domésticas e familiares, trazendo conseqüências no plano da legislação infraconstitucional, em especial nos campos do direito da família e penal. Assim, as mulheres conseguiram garantir, no artigo $226 \S 5^{\circ}$ da Lei Maior, que "os direitos e deveres referentes à sociedade conjugal são exercidos igualmente pelo homem e pela mulher". Ou seja, pelo menos juridicamente, após a inserção deste artigo, o homem já não é, por presunção social, o chefe de toda a família. 
Com relação ao tema violência, mais especificamente, a principal conquista jurídica das mulheres foi à inclusão do $\S 8^{\circ}$ no artigo 226, estabelecendo que "O Estado assegurará a assistência à família na pessoa de cada um dos que a integram, criando mecanismos para coibir a violência no âmbito de suas relações". Sem dúvida nenhuma, este dispositivo constitucional significou um inegável avanço no desvelamento do tabu da violência doméstica, reconhecendo que o Estado deveria coibir a violência na constância das relações familiares. Os frutos desta

prescrição ainda hoje estão sendo aprimorados, mediante a implementação da Lei Maria da Penha que, criminaliza os atos de violência no âmbito familiar e doméstico e/ou decorrentes de relações afetivas e conjugais.

O quadro adiante apresenta, de maneira sintética e exemplificativa, algumas demandas apresentadas pelas mulheres e suas respectivas conquistas no texto constitucional. $\mathrm{Na}$ primeira coluna estão elencadas as reivindicações e na segunda coluna estão dispostas as correspondentes normas jurídicas relativas às específicas necessidades femininas. Convém destacar que os movimentos feministas e de mulheres, ora de per si, ora por meio das parlamentares, também apresentaram um catalogado de pleitos que se converteram em normas referentes aos interesses mais gerais de toda a sociedade, não havendo espaço para destacó-los aqui. Interessa lembrar que tais reivindicações não se restringiram a uma mera formalização legal, pois as mulheres não apenas lutaram, pari passu e a seu modo, nas comissões temáticas, na tribuna, nos corredores do Congresso Nacional, nos variados momentos e com as mais diversas estratégias, como conseguiram garantir a constitucionalização de tais pleitos e, com isto, a ampliação de sua cidadania, inclusive no âmbito daquele Parlamento. 
Quadro 1- Reivindicações especificas e respectivas conquistas

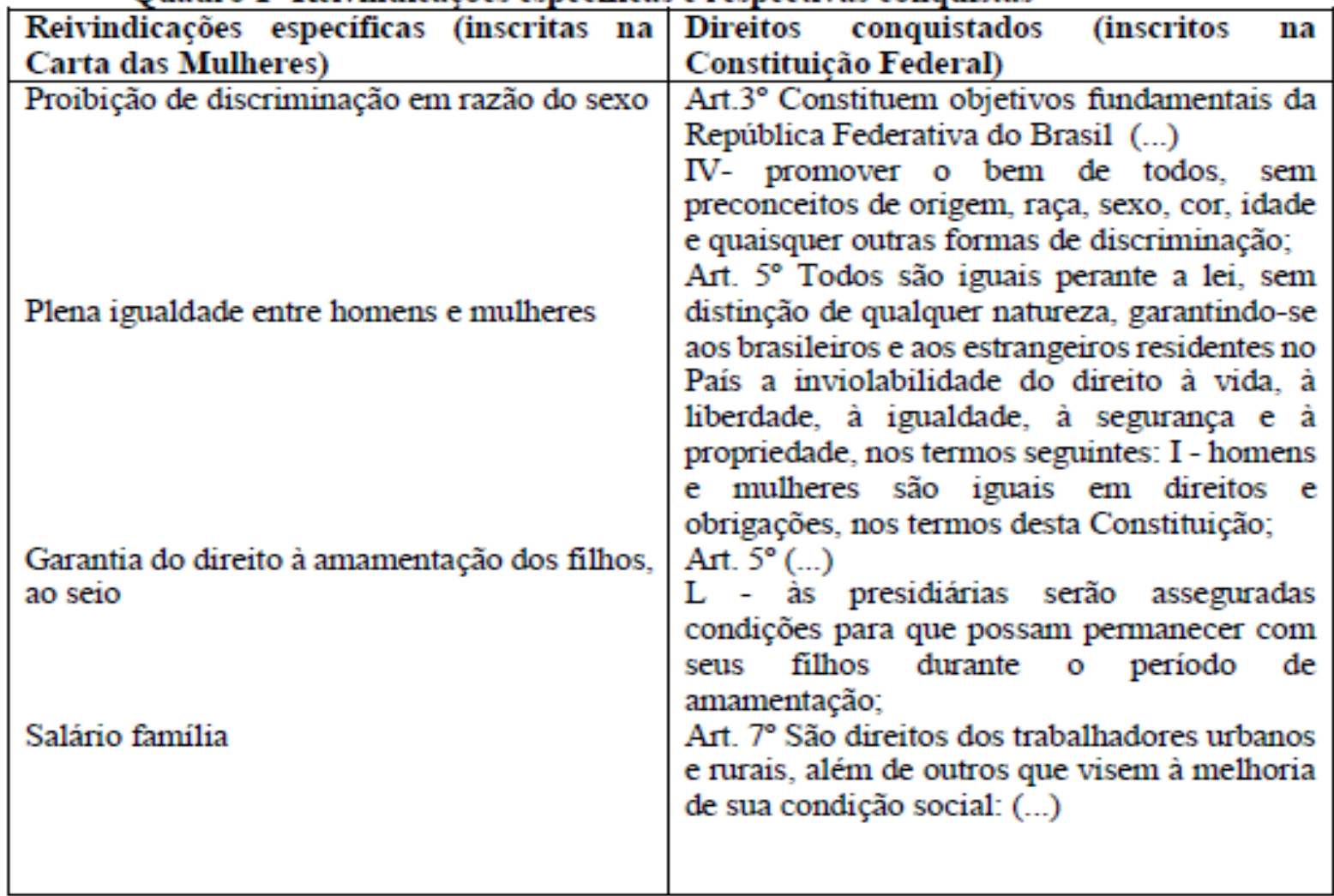


Licença matemidade

Licença paternidade

Igualdade no acesso ao mercado de trabalho e na ascensão profissional

Direito à creche

Igualdade salarial entre homens e mulheres por trabalho igual

Extensão dos direitos trabalhistas e previdenciários, de forma plena, às empregadas domésticas

Direito à posse da terra para homens e mulheres

Proteção estatal à matemidade e à gestante

Igualdade de direitos previdenciários

Direito de aposentadoria especial aos trabalhadores rurais: 50 anos de idade para as mulheres e 55 anos para os homens, bem como aposentadoria por tempo de serviço aos 25 anos para as mulheres e 30 anos para os homens, com salário integral;
XII - salário-familia pago em razão do dependente do trabalhador de baixa renda nos termos da lei;

XVIII - licença à gestante, sem prejuizo do emprego e do salário, com a duração de cento e vinte dias

XIX - licença paternidade, nos termos fixados em lei;

XX - proteção do mercado de trabalho da mulher, mediante incentivos especificos, nos termos da lei;

XXV - assistência gratuita aos fillhos $e$ dependentes desde o nascimento até 5 (cinco) anos de idade em creches e pré-escolas;

XXX - proibição de diferença de salários, de exercício de funções e de critério de admissão por motivo de sexo, idade, cor ou estado civil; Parágrafo único. São assegurados à categoria dos trabalhadores domésticos os direitos previstos nos incisos IV, VI, VIII, XV, XVII, XVIII, XIX, XXI e XXIV, bem como a sua integração à previdência social.

Art. 189. Os beneficiários da distribuição de imóveis rurais pela reforma agrária receberão títulos de domínio ou de concessão de uso, inegociáveis pelo prazo de dez anos. Parágrafo único. $O$ título de domínio e a concessão de uso serão conferidos ao homem ou à mulher, ou a ambos, independentemente do estado civil, nos termos e condições previstos em lei

Art. 201. A previdência social será organizada sob a forma de regime geral, de caráter contributivo e de filiação obrigatória, observados critérios que preservem o equilibrio financeiro e atuarial, e atenderá, nos termos da lei, a:

II - proteção à matemidade, especialmente à gestante

$\mathrm{V}$ - pensão por morte do segurado, homem ou mulher, ao cônjuge ou companheiro e dependentes, observado o disposto no $\S 2^{\circ}$.

$\S 7^{\circ} \mathrm{E}$ assegurada aposentadoria no regime geral de previdência social, nos termos da lei, obedecidas as seguintes condições: I - trinta e cinco anos de contribuição, se homem, e trinta anos de contribuição, se mulher; II - sessenta e cinco anos de idade, se homem, e sessenta anos de idade, se mulher, reduzido em cinco 


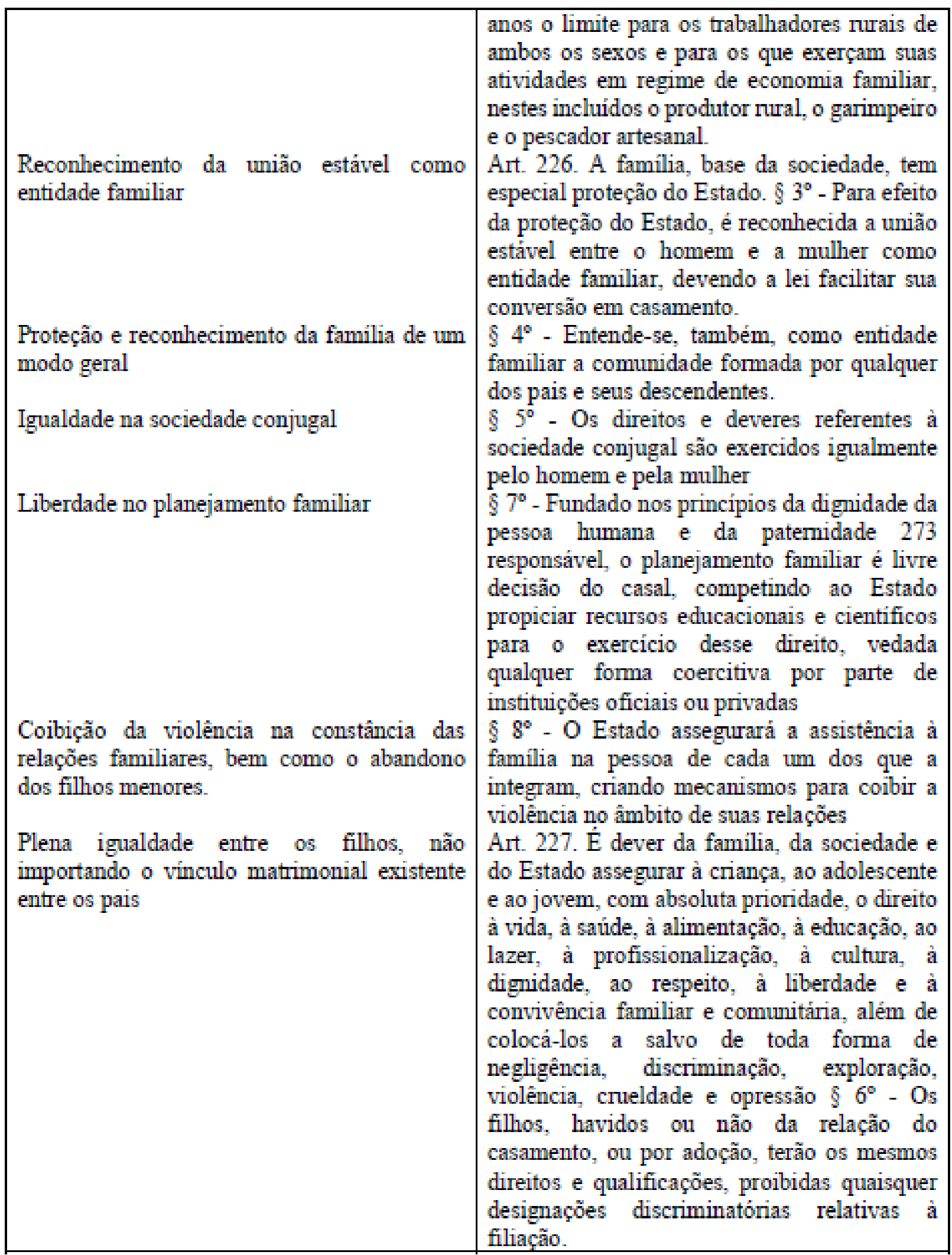

Fonte: quadro elaborado pela autora. 
Pelo exposto, não se pode mais levantar qualquer dúvida acerca da contribuição feminina para a produção da vigente Constituição do Brasil, em que pese a sub-representação política das mulheres. Tampouco se pode negar as bases feministas dos direitos constitucionais

no Brasil, obtidos no âmago de uma intervenção política feminina nunca vista ao longo de nossa história. Ademais, convém destacar que a Constituição de 1988 está em plena sintonia com as convenções e tratados internacionais de proteção aos direitos humanos pois, com base nos seus princípios de igualdade, não-discriminação e não-violência, sendo paradigma para toda a legislação infraconstitucional civil, penal, trabalhista, dentre outras; determinando, ainda que os poderes da República (Executivo, Legislativo e Judiciário) atuem consoante esta orientação.

Por força desta experiência, os movimentos feminista e de mulheres hoje no Brasil sempre destacam que os direitos fundamentais de todos os brasileiros e brasileiras, bem como os seus deveres, estão inscritos na Lei Maior e, a partir dela, torna-se obrigatória a observâncias e implementação de todas as suas regras, por todos os entes e agentes estatais de todos os poderes da nação. A Constituição Federal, portanto, é a baliza para a ação de autoridades e de particulares, pois é dela que emanam os comandos para a elaboração de políticas, de leis e de decisões judiciais. Por isto, as leis infraconstitucionais e os tratados internacionais assinados pelo Brasil devem obediência a esta Carta Política, o que lhe confere ainda mais relevo em termos de fonte para toda e qualquer reivindicação jurídica feita em âmbito nacional.

Sabe-se que até a promulgação da atual Constituição, não havia no Brasil, exceto em nível de exegese, isto é, de interpretação, a figura do tratamento isonômico entre homens e mulheres, o que deixava esta imensa parcela da população sujeita ao humor das autoridades constituídas. Não existia possibilidade de discriminação positiva em favor das mulheres nos termos da Constituição. Quer dizer, a atual Carta Política brasileira, também tecida por mãos femininas, inaugurou no plano jurídico nacional um novo horizonte para a vida em sociedade, não ignorando ou omitindo as mulheres como uma importante parcela de seus membros. 


\section{CONSIDERAÇÕES FINAIS}

Neste ano de 2015 a Constituição Federal brasileira completa 27 anos de vigência. A cada ano, tanto no âmbito acadêmico, como nos espaços de poder institucional, inúmeros eventos são realizados com vistas a relembrar o processo constituinte e propor reflexões acerca da atualidade e/ou da necessidade de regulamentação de algumas normas constitucionais. Destas discussões resultam diversos textos e reflexões que visam evidenciar os avanços e os desafios observados ao longo destes anos. No que diz respeito aos aspectos históricos e sociais do processo constituinte, importantes obras, com as mais diversas abordagens, já foram publicadas. Todavia, acerca da participação popular e, mais especificamente, sobre a participação das mulheres neste processo, as narrativas ainda são bastante acanhadas, considerando a magnitude e importância desta atuação. Assim, percebendo que a historiografia constitucional brasileira é norteada pelo que Moreno (1986) chamou de arquétipo viril protagonista da história, posto que segue ignorando ou deliberadamente omitindo a importante contribuição das mulheres no processo constituinte, buscamos, sob uma perspectiva crítica e feminista, preencher esta lacuna, evidenciando não somente a retumbante presença feminina no âmbito da Assembleia Constituinte, mas destacando a legítima reivindicação e a consequente conquista de direitos decorrentes do protagonismo das mulheres neste espaço de poder.

Pelo exposto, não resta dúvida de que, depois do lobby do batom, o modo como mulheres participam da vida política neste país nunca mais foi o mesmo, sendo incontestável que as mesmas marcaram, de forma indelével, a Constituição Federal de 1988. Porém, como é consabido, ter direitos na lei não significa o usufruto automático dos mesmos. Todavia, a previsão legal constitui importante conquista, uma vez que fortalece a luta política e gera obrigatoriedade de observância por parte do Estado e dos particulares, possibilitando sua cobrança e efetividade, seja através de ações individuais ou por meio da intervenções coletivas, notadamente por parte de grupos e movimentos sociais que, ao longo dos anos, estão se empoderando cada vez mais em termos de conhecimento de direitos e de incidência política junto às instância deliberativas e aos órgãos de justiça.

A experiência do lobby do batom articulou aspectos de democracia participativa e representativa, visando suprir o déficit de representação feminina no seio da Constituinte. Ademais, demonstrou que ambas modalidades de atuação política podem atuar conjuntamente, favorecendo o fortalecimento da democracia e o acompanhamento popular da 
ação parlamentar. Ademais disto, a atuação conjunta e muitas vezes suprapartidária das deputadas constituintes fez com que diferenças ideológicas e de caráter partidário fossem secundarizadas em nome de um interesse maior, qual seja, a avanço da cidadania feminina, provocando reflexões sobre o verdadeiro papel dos partidos políticos no Parlamento.

A partir da atuação deste grupo de pressão, e portanto ao longo destes vinte e sete anos de vigência constitucional, o feminismo que atua no âmbito do Estado acumulou uma rica experiência, ampliando a interlocução com os poderes constituídos e conquistando mais direitos para as mulheres, além de monitorar o cumprimento dos mesmos e exigir políticas públicas tendentes a efetuá-los e/ou aprimorá-los.

Vale ressaltar que, além das próprias mulheres, outros sujeitos historicamente discriminados, como crianças, adolescentes, população negra, pessoas com deficiência, idosos e presidiários, também tiveram direitos defendidos e/ou influenciados pelo lobby do batom, o que fez com que esta Carta Política, graças à aproximação estabelecida entre sociedade e Estado, viesse a ser considerada umas das mais avançadas do mundo. No entanto, questões como o direito ao aborto, a situação das domésticas (que só recentemente teve seus direitos equiparados aos demais trabalhadores) e o reconhecimento do direito à livre expressão sexual não foram contemplados neste período e seguem prejudicados pela inadimplência estatal.

Porém, é importante registar que foi graças ao lobby do batom que as demandas do movimento de mulheres e feministas passaram a ser incluídas na mais elevada agenda pública estatal, vez que temas que anteriormente eram tratados apenas pelas mulheres e seus movimentos e, no máximo, em nível infraconstitucional, foram incorporados às discussões nacionais, tais como gravidez, amamentação, creche, licença maternidade, violência domésticas, dentre outros, sendo cada vez mais debatidos e ampliados depois da criação da Secretaria Especial de Políticas para as Mulheres, em 2003, e da elaboração do Plano Nacional de Políticas para as mulheres, resultante das três grandes Conferências Nacionais, que não deixam de ser conquistas cujos alicerces foram, direta ou indiretamente, traçados pelo lobby do batom, há mais de duas décadas.

Assim sendo, pode se dizer que no Brasil, desde a histórica, ousada e paradigmática atuação das mulheres no processo constituinte, é possível manter acesa a bandeira da igualdade de gênero propugnada historicamente por mulheres e homens comprometidos com uma sociedade mais igualitária política e juridicamente falando, sendo necessário, portanto, uma outra narrativa do constitucionalismo recente. 
Convém registrar ainda que, apesar das conquistas obtidas, a interpretação e a aplicação das normas constitucionais no Brasil ainda é feita majoritariamente por homens, dado que o Judiciário em nosso país, a exemplo do Parlamento, ainda é um poder numérica e ideologicamente masculinista, fazendo-se necessário que o pensamento feminista, notadamente a teoria feminista do direito, avance também no âmbito deste poder e revolucione a maneira como se interpreta tais normas.

Ademais disto, após quase três décadas de promulgação da Constituição Federal, a participação política das mulheres no Parlamento nacional continua sendo absolutamente injusta e desproporcional a sua presença numérica no seio da sociedade e a sua participação nos diversos setores da vida pública; o que exige não somente mais reflexão feminista sobre o caráter patriarcal de nossas instituições e de nossa cultura política, mas uma maior radicalização da democracia a ser levada a cabo não apenas pelos movimentos de mulheres e feministas de nosso país, mas por todos os/as ocupantes de cargos na política formal, haja vista a sua obrigatoriedade de cumprimento do pacto social constitucionalmente estabelecido, que prevê a concretização da igualdade substancial entre homens e mulheres.

Isto dito, talvez este seja um momento propício para se fortalecer não somente os mecanismos de ampliação da participação políticas das mulheres, tais como as cotas e outros instrumentos igualmente importantes, mas de se retomar (e de se aprimorar), em nível de reforma constitucional, via constituinte exclusiva e autônoma, a ação conjunta que à época da Constituinte de 1987/88 foi estabelecida entre sociedade e Estado, considerando-se, dentre outras possibilidades, a adoção da internet, por meio do ciberfeminismo, onde, dentre outros mecanismos, sejam utilizadas as redes sociais com vistas a pressionar, monitorar e potencializar a democracia representativa e, ao mesmo tempo, seja possível desenvolver a democracia participativa, por meio da apresentação de ideias, propostas e ações voltadas para a ampliação dos direitos políticos das mulheres, fortalecendo as pontes que interligam ambas formas de participação democrática e de atuação política feminina, tudo com vistas à correção das inúmeras disparidades de gênero identificadas na vida pública da nação. Afinal, em que pese todos os esforços envidados pelos feminismos ao longo da história, fazendo uso dos mecanismos de que dispunham para lograr a completa superação de um velho paradigma, ainda vivemos, lamentavelmente, sob a hegemonia de uma cultura política socialmente deletéria, qual seja, a cultura patriarcal contra a qual é preciso que o novo constitucionalismo se insurja, a começar pela visibilização e valorização da ação política das mulheres. 


\section{REFERÊNCIA BIBLIOGRÁFICA}

AVELAR, Lúcia. Dos movimentos aos partidos: a sociedade organizada e a política formal. Revista Política e Sociedade. $N^{o}$ 11, outubro de 2007, p. 101-116. Disponível em https://periodicos.ufsc.br/index.php/politica/article/view/1310

ALVAREZ, Sonia E. Feminismos latinoamericanos. Revista Estudos Feministas, Vol. 6, No. 2, 1998, pp.:265-284.

BOBBIO, Norberto. A era dos direitos. Trad. Carlos Nelson Coutinho. Rio de Janeiro: Campus, 1992.

BRASIL. Constituição da República Federativa do Brasil: Texto constitucional promulgado em 5 de outubro de 1988. Brasília: Senado Federal, Subsecretaria de Edições Técnicas, 2006.

CADEMARTORI, Daniela Mesquita L. de; COSTA, Bernardo Leandro Carvalho. O novo constitucionalismo latino-americano: uma discussão tipológica. Revista Eletrônica Direito e Política, Programa de Pós-Graduação Stricto Sensu em Ciência Jurídica da UNIVALI, Itajaí, v.8, n.1, $1^{\circ}$ quadrimestre de 2013. Disponível em: $\underline{\text { www.univali.br/direitoepolitica }}$

CFEMEA - Centro Feminista de Estudos e Assessoria. Os direitos das mulheres na legislação brasileira pós-constituinte. Rodrigues, Almira e Cortês, Iara (orgs.) Brasília: LetrasLivres, 2006.

COSTA, Ana Alice. O movimento feminista no Brasil: dinâmicas de uma intervenção política. Revista Gênero, 2005, vol. 5, n. 2, Niterói: NUTEG/UFF, pp.: 09-35.

DALMAU, Rúben Martínez. El nuevo constitucionalismo latinoamericano y el proyecto de constituición del ecuador. Alter Justicia, n. 1. Guayaquil, oct. 2008, p. 17-27. Disponível em: http://sites.google.com/site/martinezdalmau2/AlterJustitia1.doc

DALMAU, Rúben M. Assembleas constituíntes e novo constitucionalismo em America Latina. Tempo Exterior, n 17, jul.-dic. 2008, p. 5-15. Disponível em: http://www.igadi.org/te/pdf/te_se17/te29_17_005_ruben_martinez_dalmau.pdf

FAJARDO, Raquel Yrigoyen. El horizonte del constitucionalismo pluralista: del multiculturalismo a la descolonización. In: El derecho en América Latina. Cesar Rodriguez Garavito(org). Siglo Veintiuno Editores, Buenos Aires. Novembro de 2011. p. 139-160

MITCHEL, Juliet. A mais longa revolução. Revista Civilização Brasileira, v.3, n. 14, jul. 1967, p. $5-41$.

MORAIS, José Luis Bolzan; BARROS, Flaviane de M. Novo constitucionalismo latinoamericano: o debate sobre novos sistemas de justiça, ativismo judicial e formação de juízes. Belo Horizonte: Arraes Editores, 2014.

MORENO SARDA, Amparo. El arquétipo viril protagonista de la historia: ejercicios de lectura no androcentrica. Barcelona: Ediciones LaSal, 1986. 
PHILIPIS, Anne. Género y Teoría Democrática. México: PUEG/UNAM, 1996.

PHILIPIS, Anne. De uma política das ideias a uma política da presença? Revista Estudos Feministas. Ano 9, $2^{\circ}$ semestre de 2001, p. 268-290. Disponível em http://www.scielo.br/pdf/ref/v9n1/8615.pdf.

PINTO, Celi. Mulher e Política no Brasil: os impasses do feminismo, enquanto movimento social, face às regras da democracia participativa. Revista Estudos Feminista. Número especial/2º sem. Rio de Janeiro: CIEC/UFRJ, 1994, pp. 256- 270.

PINTO, Céli Regina. Uma história do feminismo no Brasil. São Paulo: Editora Fundação Perseu Abramo, 2003.

RODRIGUES, Almira e CORTÊS, Iáris (Org). Os direitos das mulheres na legislação brasileiras pós-constituinte. CFEMEA. Brasília: Letras Livres, 2006.

SANTOS, Boaventura de Sousa. La reinvención del Estado y el Estado plurinacional. Santa Cruz de La Sierra: Alianza Interinstitucional CENDA/CEJIS/CEBID, 2007

SARDENBERG, Cecília; COSTA, Ana Alice. Feminismos no Brasil: enunciando e canalizando demandas das mulheres em sua diversidade. Labrys, estudos feministas.

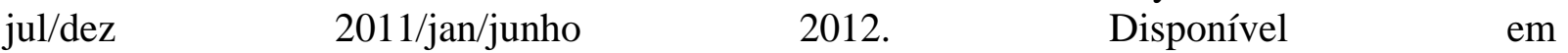
http://www.labrys.net.br/labrys20/brasil/cecilia.htm.

SILVA, Salete Maria da. A Carta que Elas Escreveram: a participação das mulheres no processo de elaboração da Constituição Federal de 1988.Tese. 320 p. (Doutorado em Estudos Interdisciplinares sobre Mulheres, Gênero e Feminismo). Faculdade de Filosofia e Ciências Humanas. UFBA. Salvador. 2012.

SILVA, Salete Maria da. O Legado jus-politico do lobby do batom vinte anos depois: a participação das mulheres na elaboração da Constituição Federal. Disponível em http://www.urca.br/ered2008/CDAnais/ pdf/SD3_files/Salete_Maria_SILVA_2.pdf Acesso em 12 jan. 2009.

TABAK, Fanny. A nova ordem legal: mulheres na constituinte. Brasília: 1989. 